\title{
Management framework paradigms for disorders of sex development
}

Mariana Telles-Silveira', Felicia Knobloch², Claudio E. Kater ${ }^{1}$

\begin{abstract}
Until 2005, questions regarding medical treatment and diagnostic information on Disorders of Sex Development (DSD) were not systematically discussed with both the patients and their families; however, the way these patients are currently treated have been changing with time. Interventional changes in the clinical-psychotherapeutic-surgical areas of DSD determine not only different medical recommendations but also help to place the patient and the family into the decisional process of therapy. We must consider two paradigmatic periods that have influenced and transformed the clinical management framework of patients with DSD: a) The "Money era" (1955), which emphasized the role of the gonads as the diagnostic criterion, having the environment as determinant of the sex identity; and b) The Chicago Consensus (2005) phase, in which the role of genetics and molecular biology was critical for an early identification, as well as in building a proper sex identity, emphasizing ethical questions and the "stigma culture". In addition, recent data have focused on the importance of interdisciplinarity and statements on questions concerning Human Rights as key factors in treatment decision making. Despite each of these management models being able to determine specific directions and recommendations regarding the clinical handling of these patients, we verify that a composite of these several models is the clinical routine nowadays. In the present paper, we discuss these several paradigms, and pinpoint clinical differences and their unfolding regarding management of DSD patients and their families. Arch Endocrinol Metab. 2015;59(5):383-90
\end{abstract}

Keywords

Sex development; gender identity; quality of life; congenital adrenal hyperplasia (CAH); psychosocial aspects; multidisciplinary teams
Disciplina de Endocrinologia e Metabologia, Departamento de Medicina, Escola Paulista de Medicina, Universidade Federal de São Paulo (EPM/Unifesp), São Paulo, SP, Brasil

${ }^{2}$ Disciplina de Psicologia, Faculdade de Ciências Humanas e da Saúde, Pontifícia Universidade Católica de São Paulo (PUCSP), São Paulo, SP, Brasil

\section{Correspondence to:}

Claudio E. Kater

Unidade de Adrenal e Hipertensão Disciplina de Endocrinologia,

Departamento de Medicina, Escola

Paulista de Medicina, Universidade

Federal de São Paulo

Rua Pedro de Toledo, $781-13^{\circ}$ andar 04039-032 - São Paulo, SP, Brasil

kater@terra.com.br

Received on June/16/2015 Accepted on June/22/2015

DOI: 10.1590/2359-3997000000084

\section{INTRODUCTION}

$\mathrm{T}$ he treatment of patients with disorders of sex development (DSD) has been changing throughout history. We will consider two representative moments that have influenced and transformed the ways patients with DSD are clinically managed: 1) primacy of environment over biology (John Money's theories, 19551990), and 2) primacy of (molecular) biology and interdisciplinarity (The Chicago Consensus, 2005). Each one has determined the ways and the guidance of the clinical handling of such patients.

Nowadays, we have access to accounts of life stories of patients with DSD through the media, patient's organizations, assistance groups, participation in scientific congresses, and autobiographical publications; thus, both patients and the scientific community have reaffirmed the importance of questioning concepts and the way in which these patients have been managed.

The influence of the theoretical and practical positions of each of these models often takes place indis- criminately in the clinic. What we observe is the presence of both in everyday clinical practice.

We recognize that knowledge development gives rise to new arrangements in the lives of those involved, and that the nomenclature created to help the management of individual cases are not neutral, as they impose a new form of connection between intervention and the physician-patient relation and the way patients are inserted in the social imaginary world under cultural and social aspects, thus determining the ways of human relationships (1). Spinola-Castro $(2,3)$ looked back at the nomenclatures used for such patients in different historic moments, showing that there were different versions on the same subject that changed according to historic and social moments.

In order to attend to the demands of the review of the different attentions given to these patients, we find it essential to discriminate the two models and their ways of managing the clinical process. That is, therefore, the aim of this paper. 


\section{Primacy of environment over biology: John Money's theories (1955-1990)}

John William Money ${ }^{1}$ was a psychologist, sexologist, researcher in gender identity, and author of countless publications, creating various concepts related to human psychosocial development. Money was a great advocate of the idea that upbringing and environment were sufficient to guarantee a healthy and consistent gender identity development for a man or a woman. In his book Sexual Signatures on Being a Man or a Woman (4), he writes:

"The moment you were born, society has taken up control of your identity (...) Whatever the situation of your chromosomes, hormones, sex organs, and individuality, their impulse could not compete with the social pressures when it came to your sexual identity" (p. 78 of the Brazilian edition).

Money presented the scientific community with convincing evidence that his theory was based on a successful experience of sex change in a normal boy who was raised as a girl (the Twins Case; see below).

In the book "Man \& Woman, Boy \& Girl...", published in 1972, Money presents, among other subjects, the Twins Case, describing the clinical follow-up of a boy who had his penis amputated during a botched circumcision when he was 7 months old. According to reports on the case, after meeting Money the parents were "convinced" that their son's sex reassignment would be the solution for the situation $(4,5)$. Since then, Money and his team started monitoring and describing the patient as a successful case of sex reassignment. It is important to highlight that the child had an identical twin, also a boy, who did not undergo circumcision and kept his male identity.

Money was considered an authority in this field owing to this experiment, which was deemed scientifically reliable, as Colapinto points out in his book "Sexo Trocado" (6), in 2001:

"The experiment had a double control, a genetic clone who, with intact penis and testicles, was raised as a boy. If the twins grew into adjusted happy children of opposite sexes, it would be an undeniable evidence of the primacy of the environment over biology in the differentiation of the sexes" (p. 13).

John W. Money (1921-2006). PhD in psychology from Harvard University, director of the Psycho-hormonal Research Unit at the Johns Hopkins Hospital, Baltimore, USA.
The concepts of sex identity, sex role, psychosocial neutrality at birth, and sexual development were transferred and used for these cases, then referred to as "Money protocols", and served as guidance for conducts in the decision regarding sex designation and even sex reassignment in children with ambiguous genitalia (7).

The concept of "gender identity" introduces the idea that human beings are not born male or female; our sex identity is shaped by environment determinants, that is, it depends on the way we are raised. As Money and Ehrhardt describe (4,5), in 1972:

"The sameness, unity and persistence of one's individuality as male or female (or ambivalent), in greater or lesser degree, especially as it is experienced in selfawareness and behavior; gender identity is a particular experience of the sex role, and the sex role, the public expression of the gender identity" (p. 12).

The concept of "gender role" is defined by the same authors $(4,8)$ as:

"Everything that a person says or does, to indicate to other or to self, the degree in which one is male or female or ambivalent; it includes, but is not limited to, sexual arousal and response; gender role is the public expression of the gender identity, and the gender identity is the private experience of the role" (p. 12).

Money and his collaborators $(4,8,9)$ also defended the idea that there was a psychosocial neutrality at birth, which would allow the assignment of any gender to the newborn, provided that the genital anatomy until two years of age (moment of the removal of diapers and the awareness of sexual differences) conferred credibility to the prescribed conduct. That is, it was up to the surgeon to adjust, correct or model the genitals to the intended behavioral phenotype.

As a result of this position, the guidance given to parents was that they should avoid any situation of ambiguity before their children. The family was guided not to talk about the treatment with the child and the child's situation from the child and the other relatives (10). It was also part of the treatment that the parents attended the psychological sessions, so that the sex reassignment or confirmation would be carried out psychologically.

\section{Clinical effects of this model}

The history of political hegemony of treatment, created and developed by John Money, has left its mark on the 
treatment of patients with DSD in such a way that we can still observe the effects and consequences of that kind of management. Without denying the advances that Money's theory has promoted in the psychological and psychosocial fields of study, as well as in the surgical area, we are going to focus, in this article, in the analysis of what is expressed by the patients and the consequences reported by them, as mentioned in the published scientific papers.

We have found the description of the following feelings and conditions in the literature search: shame, loneliness, fear (irreversible physical and psychological), pain, suicidal attempts, suicide, the feeling to be living with a secret, suspicion, and embarrassment (1117). Desire of changing sex when adolescent and/or adult (gender dysphoria), depression, social phobia, social inhibitions, anxiety disorders, and panic disorders have also been described (11-17). Besides these consequences, we find those which are observed and emphasized in specialized DSD clinics, such as: communication difficulties among physician, patient and family, silence pact, apparent aloofness towards medical appointments, difficult adherence to or discontinuation of treatment, etc. (18).

Within that perspective, three cases were explored by television and print media, describing some consequences of that ideology. The most well-known are: 1) the Twins Case $(4,5)$, described by Money and later rewritten and renamed "the John/Joan Case" (19), by Diamond and Sigmundson (see below), 2) Cheryl Chase, the founder of the first association of intersex patients in the USA (ISNA, Intersex Society of North America) (17), and 3) the Paula Case (commented in ABC's scientific series - The human body, in the episode titled: "The sexes"). We consider that these three cases, among several others, summarize, in their accounts, the direct effects of that kind of treatment, exposing this model's influences and consequences.

\section{Primacy of (molecular) biology and interdisciplinarity: The Chicago Consensus (2005)}

\section{Criticism to the Money era}

In the 1990's, Money released a book titled: "Biographies of gender and hermaphroditism...", summarizing 40 years of his work at Johns Hopkins University (20). It was eye-catching that, among the cases described in this book, the Twins Case was not mentioned as an example of the cases managed by Money. At the absence of information on the Twins Case, Milton Diamond, researcher at the University of Hawaii-Manoa, an advocate of the primacy of biology over rearing in the development of gender identity, requested the scientific community for information on the case. With data provided by Dr. H. Keith Sigmundson ${ }^{2}$, responsible for supervising the psychiatric treatment of the twin who was operated, Diamond rewrote the medical history of the case.

With the consent and the cooperation of the affected twin and his family, Diamond and Sigmundson wrote the article "Sex reassignment at birth. A longterm review and clinical implications" (19). In this article, the authors recover the data on the psychosocial development of the twin raised as a girl. The paper reveals that the patient had never accepted his sex reassignment (from male to female) and that, during adolescence, had gone through a treatment to return to his sex of birth ${ }^{3}$. By doing this, the authors widened the debate on the primacy of rearing in building gender identity, and warned practitioners of the hazards of sex change in children with DSD.

Diamond and Sigmundson state in their article that an individual's sex profile has five components: gender patterns, gender identity, reproduction, sexual mechanism and orientation (19). They claim that Money's concepts comprised only the first two items, without taking into consideration genetics and intrauterine hormonal effects.

Extensive research on hormonal influences started appearing as important determinants of gender behavior and identity in patients with DSD (21-29), as well as reviews of long-term consequences for patients treated under the previously presented regimen, showing that many of them were not satisfied with their treatment or their assigned sex (30-38). Until then, the policy used to justify the designation of a child as being a female was based on the technical limitations of the surgery, that is, on the belief that it was "easier" to construct a vagina than a penis. Along the years, that practice has been questioned, and surgeons have faced the demand for new phalloplasty techniques and the need to work

2 Psychiatrist from the city of Winnipeg, responsible for supervising and treating the twin in Canada.

3 We should mention that the "new" sex reassignment of the patient took place right after he was informed by his father of how he had been born. The family was oriented to reveal all the truth to the patient by Dr. Mary McKenty who, at the time, had decided to alter the way of conducting the case, abandoning Money's guidance and premises (6). 
together with psychologists in patient and sex partner counseling on the anatomic differences and the necessary adjustments for sexual intercourse.

That research approach, together with more comprehensive social movements, mainly regarding the body, the concept of gender, sexuality and the authority of science and medicine over patients, have resulted in changes in treatment. New protocols started being used as guides for managing patients with DSD, which led to a meeting of specialists, patients and families in Chicago, in 2005 (39).

\section{The Chicago Consensus}

In this meeting, concepts and practices in the treatment of patients with DSD were reviewed. As a first decision, the group determined a change in the terms that defined the subject conditions from the previous protocol, which fueled the association of the disorders with stigmatizing factors, for example, hermaphroditism (mythological creature). The proposal of a new nomenclature, in which the notion of Disorders of Sex Development takes the place of "Intersexual States", suggests conducts and interventions based on this new way of diagnosing. Molecular biology and genetics then start having a prominent place in the discussions.

Every child should have an assigned sex, but definite, irreversible surgical interventions should be guided by medical decisions and neither by cosmetic reasons nor to guarantee the development of gender identity. Moreover, the decisions should be discussed with parents and centered on the individual's needs and on the right diagnosis of the disease.

In short, the Chicago Consensus have decided that:

“(a) gender assignment must be avoided before expert evaluation of the in newborn; (b) evaluation and long-term management must be performed at a center with an experienced multidisciplinary team; (c) all individuals should receive a gender assignment; (d) open communication with patients and families is essential, and (e) participation in decision-making is encouraged; and (f) patient and family concerns should be respected and addressed in strict confidence, and (g) the importance of support groups both for families and the patients should not be discarded".

The guidelines of secrecy/concealment previously adopted were substituted by open debates on the way of guiding and telling patients about what they have, how they were born, and which decisions were taken during their childhood, called "information management" (11). In addition, some articles also emphasize the need to include the child in the decision-making, and to adjust the medical terms to lay language $(3,11,12,16-18,22,35,40-47)$.

Since the Chicago meeting, in time to resume the discussions started in 2005, a new document appears, resulting from the meeting of the Swiss National Advisory Commission on Biomedical Ethics NEK-CNE, titled: "On the management of differences of sex development. Ethical issues relating to "intersexuality", published in 2012 (48). This document is the resulting work of that commission and consists of the presentation of ethical aspects related to intersexuality, mainly regarding questions of sex development and surgical procedures, building a counseling view of information for parents, patients and professionals. We should point out that the conclusions in that document are not universal, representing specific sociocultural aspects.

The document also underlies the importance of removing the cases of DSD from the list of "medical emergencies". They highlight the importance of the child's well-being as the guide in the new treatment perspective, especially concerning questions related to psychosocial development and to surgical procedures. With these guidelines, the DSD return to the status of chronic disease, losing the exceptionality quality the cases had been assigned with. They recommend that the term "disorders" be replaced by "differences" or "variations" of sex development $(40,48)$, claiming that that term perpetuates the question of stigma, causing the subjects shame and placing them in a list of disorders.

The Swiss commission withdraws the importance of corrective surgery in maintaining gender identity. Its foundation is the idea that, even with correction, the genitals of a child with DSD will never be identical to the ones of a child who is born without genital ambiguity. Interventions should be suitable for the needs of each individual, and whenever possible, the child should be able to express his/her opinion. However, as Hiort emphasizes, it is the parents' right to care for their children in a way that seems best to them, including the option of corrective surgery. It is up to the professionals involved to discuss the pros and cons of any situation (40).

Together with the ideas presented in the document designed by the commission, biological and medical knowledge, through the discovery of new genes involved in sex differentiation as well as the hormonal 
influences in the brain development of sex identity, triggered a revolution in the way these patients are seen today. Not to mention the global changes in cultural conventions that also allowed greater tolerance towards cases of ambiguous genitalia and sexual diversity (LGBTT movement $)^{4}$.

On October 30, 2013, the Internet website "Terra" featured a story titled: "Germany is the first European country to recognize third gender" (49), describing the legal revolution related to cases of patients with DSD, guaranteeing by means of a law that children or adolescents be able to express their opinion on the sex they want to be officially registered, through the alternative of having in their birth certificate the option of "undefined category". The measure was taken so that parents did not feel under pressure to make decisions and could be legal backing. The law, as the article points out, is recent and controversial.

Along the same lines, on November 10, 2013, another story was published: "Activists demand the prohibition of surgeries in hermaphrodite babies in Germany" (50); this time, reassured with the new law, the activists requested the prohibition of any surgery, claiming that the law should protect the children from having their physical integrity violated. The activists based their claims on accounts of patients who stated they had gone through those experiences as routine invasive procedures (referring to vaginal dilating exams and regular visits to surgeons' offices). They propose that the law should protect these children until they are 16 years old.

The role of surgery has been changing together with these new demands; there are accounts of cases in the literature that were poorly conducted in infancy, and others that have benefit from corrective surgery $(3,40,51,52)$. It is understood that it is always important to give parents advice as to the benefits and risks of surgery, clearing out all procedures possible. It is up to the surgeon to have solid knowledge of the genitalia's anatomy and embryology (53). The main argument of professionals who are for surgery is that we might remove the patients from everyday social life as intersex beings (3). In Brazil, two works confirm the idea that, when the clinical-surgical proposal is well defined, the long-term results for the patient's "quality of life" are

\footnotetext{
4 Social movement against discrimination and in defense of the rights of LGBTT (lesbians, gays, bisexuals, transsexuals, and transgenders).
}

satisfactory (51), while patients treated later on in life, when questioned about treatment, say they would have liked to have the option of surgery in infancy (51).

Today, with the advances and changes in the treatment of patients with DSD, professionals are increasingly embracing the movement of health management policies, concerned with the quality of life of their patients. In order to reach that same objective, specialized centers have been oriented towards dealing with psychosocial and psychosexual aspects. These aspects are related to: a) assessing gender assignment; b) the moment of medical interventions, as well as their results and consequences; c) sexuality and sexual orientation, d) information management (how patients should know about their diagnosis) and, e) quality of life $(11,12,32,51,52,54)$. In order to handle these aspects, favoring the development of patient's and family's autonomy, according to Brian and Hiort $(55,40)$, it would be important that the specialized centers for DSD combined with guarantee that the information from childhood have a continuity until adult life, thus avoiding that these subjects be fragmented within different services.

A few studies have focused on the DSD patient's quality of life, be it due to how rare the cases or to the difficulty in keeping these patients in only one center. Amaral and cols. (52) analyzed nine studies on the theme, which showed, both in developed and developing countries, that the evaluation of the quality of life varied from "very poor" to "similar to the normal population" or even "better than the normal population". However, patients who were treated later on in life had the most jeopardized quality of life (52).

\section{Clinical consequences}

The proposals created almost 10 years ago at the Chicago meeting are still under evaluation and implementation in large centers; for that reason, there is little scientific data sufficiently schematized for a more rigorous evaluation of the advantages and disadvantages of this new protocol. However, we noticed that when a more technical relation with the codified terms is emphasized $^{5}$, the nomenclature leads the subject to a more medicalized place.

Under a certain perspective, we can say that a direct consequence of that model is that the cases of DSD,

5 The karyotype is associated to the name/abbreviation of the disease, for example: DSD 46,XX ovotesticular. 
when legitimated in the medical domain, could somehow leave anonymity and gain space in society, being more socially included and leaving behind the marginality in which the bizarre placed them and where they were forced to live. A direct consequence of the Chicago proposal and of the position adopted by the letter of the Swiss Commission is the emphasis on subjectivity and in the intersubjective relationships, highlighting aspects related to the patients' human rights. The discussion over the new nomenclature for the DSD implied, therefore, rethinking the clinical handling and a management structure to receive these patients and their families. In many aspects, revising the nomenclature was important, especially concerning the stigma connotation that the names of the disorders carried and the fact that including aspects of molecular biology is a good way for practitioners to convey their students a clinical reasoning about the cases.

However, as Damiani and Guerra-Junior (56) pointed out, the new terms did not solve the problems of the culture of stigmatization by simply adding the codes $46, \mathrm{XX}$ and $46, \mathrm{XY}$ to the name of the disorder. According to these authors, the group of specialists in Chicago underestimated the patients and their families when they determined that the diagnosis should not be based only on the gonads but also on the chromosome constitution. For them, adding the karyotype to the name of the dysfunction does not seem enough or correct, because it keeps the same problems that the consensus tries to solve. In spite of "believing" that these are secret codes, that form of designation seems to increase patient's and family's suspense and anxiety, as many times they try to solve the riddle by themselves, usually through the convenient access to the Internet.

When questioned about the stigmas and the initial approach with babies with DSD, Lee and Houk could state in the lecture titled "Initial management of patients with DSD", presented at the International Congress of Pediatric Specialties ${ }^{6}$, that the consensus is not a set of rules but a set of guidelines to help the interdisciplinary team, and that each case should be seen in its particularity, taking into consideration their cultural, religious and familiar differences.

A direct consequence of the two protocols concerns the debate on how the development of gender iden-

"Lee and Houk - "Criança 2010" - III Congresso Internacional de Especialidades Pediátricas, in Curitiba, August 28 to 31,2010 . tity takes place. With the failure of the Twins Case, the theory of the primacy of rearing over biology needed to be reviewed and, until today, researchers from various fields discuss the construction of new postulates and explanatory theories. Radical attitudes, therefore, lead to serious mistakes, since defining identity seems to be a multifactorial process (57).

Since it is no longer a matter of convincing the patients about their gender identity, it is up to the therapist to give support to the development of the construction of psychosocial aspects, considering all the complexity involved in the process. Under the new norms of the protocol, the possibility of a future change of sex is not considered a treatment failure.

Without questioning, the positions in face of advances in biology and scientific technology related to this subject, what we see is a shift in emphasis when dealing with DSD patients: the importance given to caring for quality in the relationships among all those affected by the situation - physician, family and patient (following the tendency for humanization of health, by emphasizing biopsychosocial aspects, counterbalancing the primacy of biomedical aspects). The child's wellbeing and love should guide the treatment conducts, so that in the future the parents can tell their children why they made those decisions. This way, the partnership among teams and families should be the closest possible, bearing in mind that all of them are tending a central aspect of the child's personality - the development of sexuality and gender identity (12,18,34,48,58-61).

For that reason, working with the subjectivity of those involved is essential under this model, when not only scientific guidance determines the medical procedures. It is a complex field, as the medical tradition has always been focused on the capacity of biomedical parameters and where feelings are extinguished or put aside. In order to accomplish that, it is necessary to create tools for educational training and spaces for discussion so that the teams can deal with their own anxieties, providing a place for the young physician to learn how to handle not only the psychical questions that emerge during clinical management but also all the standstills that arise within teams that make shared decisions.

\section{DISCUSSION}

We are most definitely witnessing the development of a new paradigm, a new model of assistance for managing patients with DSD. The effects of working the same way 
for forty years will probably still echo for many years in everyday clinic. For that reason, making explicit the models of management proposed is important and necessary to take up different ways of clinical handling. We believe that the two proposals mentioned above may coexist and have a part in the clinical history reported by the patients, especially because they approach different dimensions of the problems. The challenge will certainly be to keep a connection between the particularities of the medical clinic and the psychosocial questions. Discriminating them, therefore enable a more precise assessment of the information our patients have received throughout their lives, thus allowing them to construct more effective therapeutic proposals that are particular for each one of them.

For the family and patient to have a more active participation, it is necessary that new clinical strategies be constructed for dealing with relationship and subjective matters, as well as the development of tools for educational training, spaces for discussion, so that the teams can deal with their own anxieties. New studies are rising and contributing to widen the countless questions involved in such a complex clinic, but long-term papers are still needed so that we can assess the changes in these ways of managing everyday clinical practice.

Acknowledgements: we like to thank the patients at the Adrenal Outpatient Clinic (AOC) at Escola Paulista de Medicina of Universidade Federal de São Paulo (EPM/Unifesp), the coworkers at AOC, and Capes (Coordenação de Aperfeiçoamento de Pessoal de Nivel Superior) for funding Mariana Telles Silveira's PhD scholarship during this project (2010-2014).

Disclosure: no potential conflict of interest relevant to this article was reported.

\section{REFERENCES}

1. Foucault M. Herculine Barbin: o diário de um hermafrodita. Rio de Janeiro: Francisco Alves; 1983. 175 p.

2. Spinola-Castro AM. A importância dos aspectos éticos e psicológicos na abordagem do intersexo. Arq Bras Endocrinol Metab. 2005;49(1):46-59.

3. Spinola-Castro AM. Aspectos históricos e éticos dos distúrbios da diferenciação do sexo. In: Maciel-Guerra AT, Guerra-Junior G, organizadores. Menino ou menina? Distúrbios da diferenciação do sexo. $2^{\text {a }}$ ed. Rio de Janeiro: Rubio; 2010. p. 455-79.

4. Money J,Tucker P. Sexual signatures on being a man or a woman. Boston: Little Brown \& Co; 1976.

5. Money J, Ehrhardt AA. Man: and woman, boy and girl - the differentiation and dimorphism of gender identity from conception to maturity. Baltimore: Johns Hopkins University Press; 1972. 311 p.

6. Colapinto J. Sexo trocado - A história real do menino criado como menina. Rio de Janeiro: Ediouro; 2001. 304 p.
7. Corrêa M. Não se nasce homem. Encontro "Masculinidades/Feminilidades" (Encontros arrábida). Portugal, 2004. Available from: $<$ http://social.stoa.usp.br/articles/0016/4388/nA_o_se_nasce_ homem.pdf>.

8. Money J, Ehrhardt AA. Gender dimorphic behavior and fetal sex hormones. Recent Prog Horm Res. 1972;28:735-63.

9. Money J, Hampson JG, Hampson JL. Hermaphroditism: recommendations concerning assignment of sex, change of sex and psychologic management. Bull Johns Hopkins Hosp. 1955;97(4):284-300.

10. Fausto-Sterling A. Sexing the body: gender politics and the construction of sexuality. New York: Basic Books; 2000. 496 p.

11. Cohen-Kettenis PT. Psychosocial and psychosexual aspects of disorders of sex development. Best Pract Res Clin Endocrinol Metab. 2010;24(2):325-34.

12. Meyer-Bahlburg HFL. Treatment guidelines for children with disorders of sex development. Neuropsychiatr Enfance Adolesc. 2008;56(6):345-9. Available from: <http://www.sciencedirect.com/ science/article/pii/S0222961708001207>.

13. Kleinemeier $E$, Jürgensen $M$, Lux A, Widenka PM, Thyen U; Disorders of Sex Development Network Working Group. Psychological adjustment and sexual development of adolescents with disorders of sex development. J Adolesc Health. 2010;47(5):463-71.

14. Reisch N, Arlt W, Krone N. Health problems in congenital adrenal hyperplasia due to 21 -hydroxylase deficiency. Horm Res Paediatr. 2011;76(2):73-85.

15. Telles S. O caso de David Reimer e a questão da identidade de gênero. Psychiatry online Brasil. 2004:9(6). Available from: <http://www.polbr.med.br/ano04/psi0604.php\#cima>.

16. Munõz EC. Case 1 Part III (Los estados intersexuales y los tratamientos médicos dominantes). 2004. Available from: <http:// www.isna.org/node/34>.

17. Chase $C$. What is the agenda of the intersex patient advocacy movement? First World Congress: Hormonal and Genetic Basis of Sexual Differentiation Disorders, Tempe Arizona, May 17-18, 2002. Available from: <http://www.isna.net/>.

18. Telles-Silveira M,Tonetto-Fernandes VF, Schiller P, Kater CE. Hiperplasia adrenal congênita: estudo qualitativo sobre doença e tratamento, dúvidas, angústias e relacionamentos (parte I). Arq Bras Endocrinol Metab. 2009;53(9):1112-24.

19. Diamond M, Sigmundson HK. Sex reassignment at birth. Longterm review and clinical implications. Arch Pediatr Adolesc Med. 1997;151(3):298-304.

20. Money J. Biographies of gender and hermaphroditism in paired comparisons: clinical supplement to the handbook of sexology. New York: Elsevier; 1991. 375 p.

21. Jordan-Young RM. Hormones, context, and "brain gender": a review of evidence from congenital adrenal hyperplasia. Soc Sci Med. 2012;74(11):1738-44.

22. Öçal G. Current concepts in disorders of sexual development. J Clin Res Pediatr Endocrinol. 2011;3(3):105-14.

23. Berenbaum SA, Beltz AM. Sexual differentiation of human behavior: effects of prenatal and pubertal organizational hormones. Front Neuroendocrinol. 2011;32(2):183-200.

24. Hines M. Gender development and the human brain. Annu Rev Neurosci. 2011;34:69-88.

25. Damiani D, Damiani D, Ribeiro TM, Setian N. [Brain sex: just beginning to pave the way]. Arq Bras Endocrinol Metab. 2005;49(1):37-45.

26. Diamond M. Prenatal predisposition and the clinical management of some pediatric conditions. J Sex Marital Ther. 1996;22(3):13947.

27. Pasterski V, Geffner ME, Brain C, Hindmarsh P, Brook C, Hines M. Prenatal hormones and childhood sex segregation: playmate and 
play style preferences in girls with congenital adrenal hyperplasia. Horm Behav. 2011;59(4):549-55.

28. Hines M. Sex-related variation in human behavior and the brain. Trends Cogn Sci. 2010;14(10):448-56.

29. Hines M. Early androgen influences on human neural and behavioural development. Early Hum Dev. 2008;84(12):805-7.

30. Nordenström A, Frisén L, Falhammar H, Filipsson H, Holmdahl G, Janson PO, et al. Sexual function and surgical outcome in women with congenital adrenal hyperplasia due to CYP21A2 deficiency: clinical perspective and the patients' perception. J Clin Endocrinol Metab. 2010;95(8):3633-40.

31. Telles-Silveira M, Tonetto-Fernandes VF, Schiller P, Kater CE. Hiperplasia adrenal congênita: estudo qualitativo sobre definição e redefinição sexual, cirurgia de dilatação e apoio psicológico (parte II). Arq Bras Endocrinol Metab. 2009;53(9):1125-36.

32. Lee PA, Houk CP, Husmann DA. Should male gender assignment be considered in the markedly virilized patient With $46, \mathrm{XX}$ and congenital adrenal hyperplasia? J Urol. 2010;184(4 Suppl):1786-92.

33. Creighton SM, Liao LM. Changing attitudes to sex assignment in intersex. BJU Int. 2004;93(5):659-64.

34. Johannsen TH, Ripa CP, Carlsen E, Starup J, Nielsen OH, Schwartz $M$, et al. Long-term gynecological outcomes in women with congenital adrenal hyperplasia due to 21-hydroxylase deficiency. Int J Pediatr Endocrinol. 2010;2010:784297.

35. Lee PA, Schober J, Nordenstrom A, Hoebeke P, Houk C, Looijenga $L$, et al. Review of recent outcome data of disorders of sex development (DSD): emphasis on surgical and sexual outcome. J Pediatr Urol. 2012;8(6):611-5.

36. Fagerholm R, Santtila P, Miettinen PJ, Mattila A, Rintala R, Taskinen $\mathrm{S}$. Sexual function and attitudes toward surgery after feminizing genitoplasty. J Urol. 2011;185(5):1900-4.

37. Fagerholm R, Mattila AK, Roine RP, Sintonen H, Taskinen S. Mental health and quality of life after feminizing genitoplasty. J Pediatr Surg. 2012;47(4):747-51.

38. Crouch NS, Liao LM, Woodhouse CR, Conway GS, Creighton SM. Sexual function and genital sensitivity following feminizing genitoplasty for congenital adrenal hyperplasia. J Urol. 2008;179(2):634-8.

39. Lee PA, Houk CP, Ahmed SF, Hughes IA; International Consensus Conference on Intersex organized by the Lawson Wilkins Pediatric Endocrine Society and the European Society for Paediatric Endocrinology. Consensus statement on management of intersex disorders. International Consensus Conference on Intersex. Pediatrics. 2006;118(2):e488-500.

40. Hiort O, Birnbaum W, Marshall L, Wünsch L, Werner R, Schröder $\mathrm{T}$, et al. Management of disorders of sex development. Nat Rev Endocrinol. 2014;10:520-9.

41. Houk CP, Lee PA. Update on disorders of sex development. Curr Opin Endocrinol Diabetes Obes. 2012;19(1):28-32.

42. Liao LM, Green H, Creighton SM, Crouch NS, Conway GS. Service users' experiences of obtaining and giving information about disorders of sex development. BJOG. 2010;117(2):193-9.

43. Kogan BA, Gardner M, Alpern AN, Cohen LM, Grimley MB, Quittner AL, et al. Challenges of disorders of sex development: diverse perceptions across stakeholders. Horm Res Paediatr. 2012;78(1):40-6.

44. Palmer BW, Wisniewski AB, SchaefferTL, Mallappa A, Tryggestad $\mathrm{JB}$, Krishnan S, et al. A model of delivering multi-disciplinary care to people with 46 XY DSD. J Pediatr Urol. 2012;8(1):7-16.

45. Bradley SJ, Oliver GD, Chernick AB, Zucker KJ. Experiment of nurture: ablatio penis at 2 months, sex reassignment at 7 months, and a psychosexual follow-up in young adulthood. Pediatrics. 1998;102(1):e9.
46. Schaeffer TL, Tryggestad JB, Mallappa A, Hanna AE, Krishnan S, Chernausek SD, et al. An Evidence-Based Model of Multidisciplinary Care for Patients and Families Affected by Classical Congenital Adrenal Hyperplasia due to 21-Hydroxylase Deficiency. Int J Pediatr Endocrinol. 2010;2010:692439.

47. Romao RL, Salle JL, Wherrett DK. Update on the management of disorders of sex development. Pediatr Clin North Am. 2012;59(4):853-69.

48. Swiss National Advisory Commission on Biomedical Ethics NEK-CNE. On the management of differences of sex development ethical issues relating to intersexuality. 2012. Available from: <www.nekcne.ch>.

49. Alemanha é o primeiro país europeu a reconhecer terceiro gênero. 2013. Available from: <http://noticias.terra.com.br/mundo/ europa/alemanha-e-o-primeiro-pais-europeu-a-reconhecer-terceiro-genero,8ac268fadb402410VgnCLD2000000dc6eb0aRCRD. html>.

50. UOL Notícias/Jornais - Der Spiegel. Available from: <http://noticias.uol.com.br/jornais/internacionais/der-spiegel/>.

51. Cassia Amaral $R$, Inacio $M$, Brito VN, Bachega TA, Oliveira AA $\mathrm{Jr}$, Domenice $\mathrm{S}$, et al. Quality of life in a large cohort of adult Brazilian patients with $46, X X$ and $46, X Y$ disorders of sex development from a single tertiary centre. Clin Endocrinol (Oxf). 2015;82(2):274-9.

52. Amaral RC, Inacio M, Brito VN, BachegaTA, Domenice S, Arnhold IJ, et al. Quality of life of patients with $46, X X$ and $46, X Y$ disorders of sex development. Clin Endocrinol (Oxf). 2015;82(2):159-64.

53. Miranda ML, Bustorff-Silva JM. Correção cirúrgica das ambiguidades genitais durante a infância. In: Maciel-Guerra AT, GuerraJúnior G, organizadores. Menino ou menina? Distúrbios da diferenciação do sexo. $2^{\mathrm{a}}$ ed. Rio de Janeiro: Rubio; 2010. 421-32 p.

54. Costa-Barbosa FA, Telles-Silveira M, Kater CE. Hiperplasia adrenal congênita em mulheres adultas: manejo de antigos e novos desafios. Arq Bras Endocrinol Metab. 2014;58(2):124-31.

55. Brain CE, Creighton SM, Mushtag I, Carmichael PA, Barnicoat A, Honour JW, et al. Holistic management of DSD. Best Pract Res Clin Endocrinol Metab. 2010;24(2):335-54.

56. Damiani D, Guerra-Júnior G. As novas definições e classificações dos estados intersexuais: o que o Consenso de Chicago contribui para o estado da arte? Arq Bras Endocrinol Metab. 2007;51(6):1013-7.

57. Paiva e Silva RB, Suzigan LZC. Aspectos psicológicos. In: MacielGuerra AT, Guerra-Júnior G, organizadores. Menino ou menina? Distúrbios da diferenciação do sexo. $2^{\mathrm{a}}$ ed. Rio de Janeiro: Rubio; 2010. 373-80 p.

58. Guerra-Júnior G, Ceschini M, Marques-de-Faria AP, Paiva e Silva RB, Maciel-Guerra AT. A importância da interdisciplinaridade no atendimento dos pacientes com distúrbios da diferenciação do sexo em hospital universitário. In: Maciel-Guerra AT, GuerraJúnior G, organizadores. Menino ou menina? Distúrbios da diferenciação do sexo. $2^{\mathrm{a}}$ ed. Rio de Janeiro: Rubio; 2010. 451-4 p.

59. Speiser PW, Azziz R, Baskin LS, Ghizzoni L, Hensle TW, Merke DP, et al.; Endocrine Society. Congenital adrenal hyperplasia due to steroid 21-hydroxylase deficiency: an Endocrine Society clinical practice guideline. J Clin Endocrinol Metab. 2010;95(9):4133-60.

60. Ferrari VRB. Anomalias da diferenciação sexual: aspectos psicológicos. In: Setian N, editor. Endocrinologia pediátrica - aspectos físicos e metabólicos do recém-nascido ao adolescente. $2^{\mathrm{a}}$ ed. São Paulo: Sarvier; 2002. 465-72 p.

61. Lima IMSO, Toralles MBP, Fraser RTD. Direitos da criança e distúrbios de diferenciação do sexo: além da família. In: Maciel-Guerra AT, Guerra-Júnior G, organizadores. Menino ou menina? Distúrbios da diferenciação do sexo. $2^{\text {a }}$ ed. Rio de Janeiro: Rubio; 2010. 479-95 $\mathrm{p}$. 